\title{
DEPRESSION AND ANXIETY LEVELS AMONG CHRONIC KIDNEY PATIENTS
}

\author{
Selvira Draganovic, \\ International University of Sarajevo, Bosnia and Herzegovina
}

Baha Kurulmaz,

Independent researcher

\begin{abstract}
Chronic kidney disease is a progressive and irreversible loss of the kidney function. Besides physical and treatment complications for chronic kidney disease, kidney patients also suffer a number of psychological problems, among which depression and anxiety are very common. This all, not only makes chronic kidney patients', already difficult life, more difficult but also furthermore vulnerable and at risk for earlier death. This study aimed to measure the level of anxiety and depression of chronic kidney disease patients have been measured and compared with the scores of healthy participants. Since haemodialysis is the most common treatment method for CKD, 60 haemodialysis patients at Inegol hospital in Turkey and 60 people from a general healthy population $(\mathrm{N}=120)$ were conveniently chosen to participate in this study. Following the literature review indicating possible psychological outcomes of chronic kidney failure and haemodialysis, depression and anxiety level among CKD patients and healthy cohort group was measured. Depression and anxiety levels were investigated using the Beck Depression Inventory II and The State-Trait Anxiety Inventory were used (Turkish versions). Study results indicate, when compared to healthy cohorts $(\mathrm{M}=12.66$, s.d. 5.7), CKD patients scored higher on depression scale $(M=18.5$, s.d. 7.3) as well as higher
\end{abstract}


level of anxiety $(\mathrm{M}=40.76$, s.d.10.7) when compared with a healthy population $(\mathrm{M}=32.40$, s.d. 7.8$)$. Results of this study, next to important scientific contribution, indicate importance and the need for professional help psychological support for chronic kidney disease patients in order to diminish the psychological impact of facing chronic illness.

Keywords: Chronic kidney disease, depression, anxiety, chronic kidney patients, a general population 


\section{INTRODUCTION}

Chronic kidney disease, also called, end-stage renal disease is becoming one of the major public health concerns all over the world. The prevalence of end-stage renal disease (ESRD) is expected to rise around 7\% of the whole World population and this will cost about 1.1 trillion dollars in medical expenditures (Lysaght, 2002). According to the Turkish Public Health Institute (2014), the prevalence of chronic kidney disease in Turkey is $15.7 \%$ which means 7.5 million people have been diagnosed with chronic kidney disease. The same source indicates increasing number of hemodialysis patients stating the number increased 3.6 times from1995 to 2014 (The Ministry of Health of Turkey, 2014). Since there is no cure for CKD, kidney transplant or dialysis are the most common treatment methods. Hemodialysis, although generally provided at hemodialysis centers at hospitals it is also possible to get home dialysis but research indicates more positive outcomes of hemodialysis in hospitals (National Institute of Diabetes and Digestive and Kidney Diseases, 2016). Besides facing chronic physical health condition, although rarely timely and properly diagnosed, chronic kidney patients face several psychological problems such as anxiety and depression. Despite poor chances to diagnose psychological problems of CKD patients, depression is the most common psychological problem among CKD patients (Bossola et al., 2010) and it is found to be very much prevalent among CKD patients, affecting up to $20 \%$ of CKD patients even before the initiation of dialysis (Hedayati et al., 2009). At the same time, there is a bidirectional relationship between depression and 
chronic medical illnesses due to the health risk behaviors and changes in the brain caused by depression which, in turn, increases the risk for chronic medical illnesses (Katon, 2011). Besides physical changes in chronic kidney patients (Goldberg, 2010) which might underlie the development of depression, other possible reasons for depression development among chronic illness patients are related to experiencing multiple pain (Dworkin et al.,1990), and stress due the change of lifestyle (Prince et al., 2007). Additionally, expected and commonly occurring decrease in the overall quality of life of chronic kidney patients makes patients more prone to develop psychological problems such as depression and anxiety (Ottaviani et al., 2016). Chronic kidney patients report experiencing symptoms which match with the symptoms of major depression such as, anhedonia and feelings of sadness, helplessness, guilt, hopelessness, which are usually accompanied by changes in sleep, appetite, and libido (Finkelstein, 2016). Furthermore, chronic kidney patients report experiencing high anxiety levels during hemodialysis treatment, because it enables and triggers their thinking about the long-term health condition, survival and early mortality, financial issues, job status and fear of losing a job and getting the treatment (Acar, 2007). Anxiety, as an emotional reaction which is primarily characterized by feelings of tension and physical changes, affects the cognitive process (Cates et al., 1996). Physical symptoms of anxiety among CKD patients are shown in chest pain, sweating, breathlessness, palpitations with the strong cognitive component in a form of the fear of dying. Given the multiplicity of issues to worry about and strong apprehension feeling due to the dialysis 
process; being hooked to hemodialysis machine working as an artificial kidney, with an establishment vascular access on their arms, monitoring the dialysate, the fluid cleaning unwanted waste products from patient's blood and, abundance of medications like analgesic, antimicrobial, hypoglycemic, diuretic, antihypertensive, erythropoietin (Sari, 2016) and potential medical complications (Sousa, 2008), chronic kidney patients face multiple physical strains and psychological challenges. Chronic kidney patients are usually very weak following hemodialysis treatment; depend on others to take them to and from hospitals or private clinics, thus requiring care and support during and after the treatment. This might be additional vulnerability chronic patients feel besides the illness itself, making them vulnerable and prone to develop depression and anxiety (Kocabaşoğlu, 2004). With this study, we aim at investigating the level of depression and anxiety among chronic kidney patients and the healthy control group.

\section{Methodology}

\section{Sample}

This study has been done on a sample of 120 participants, comprising two groups, experimental and control. The experimental group consisted of 60 chronic kidney patients on hemodialysis ( 27 females and 33 males) at Inegöl Hospital in Turkey, and the equivalent of 60 people in control group (from different parts of Inegöl city) as representatives of the general healthy 


\section{Epiphany: Journal of Transdisciplinary Studies}

population. All participants were over 50 years of age. The convenient sampling method was used for participants' selection with the diagnosis of chronic kidney disease diagnosis and no chronic kidney diagnosis as a primary selection.

\section{Procedure}

After contacting the administration of Inegöl Public Hospital and acquiring permission to contact hemodialysis patients, chronic kidney patients were approached. Following ethical consideration, researcher (Baha Kurulmaz) found $60 \mathrm{CKD}$ patients, explained study aims and objective (ensuring confidentiality) inquired their willingness to participate in the study, after what they all agreed. Given their health condition, the researcher chose to ask participants all questions, one by one, and circled their responses. Participation was voluntary and all went well. After collecting the data from experimental group, researcher reached 60 people, older than 50 years of age (in order to match experimental group), explained study aim and asked them to participate in the study. After they agreed, researcher again (to follow the same procedure) asked participants all questions, one by one, and circled their responses. Collected data has been entered into SPSS 20, which was used to analyze and evaluate data collected.

\section{Research questions and hypothesis}

This study aimed to investigate depression and anxiety levels among chronic kidney patients, experimental, and healthy control group. 


\section{Hypotheses}

H1: Chronic kidney patients will score higher on depression scale compared to the general population

H2: Chronic kidney patients will score higher on anxiety scale compared to the general population.

\section{Measurements}

To measure depression and anxiety level of participants, two scales were used, Beck Depression Inventory and level in study groups we used Beck Depression Inventory BDI and State-Trait Anxiety Inventory STAI. BDI (created by A. T. Beck), is a 21-item self-report test presented in a multiplechoice format, which measures presence and degree of depression in adolescents and adults consistent with the DSM-5, evaluating 21 symptoms of depression, 15 of which cover emotions, four cover behavioral changes, and six somatic symptoms. Each answer is scored on a scale value of 0-3. Between 1-10 these ups and downs are considered normal, between 1116 mild mood disturbances, between 17-20 borderline clinical depression, between 21-30 moderate depression, between 31-40 severe depression and over 40 extreme depression.

The State-Trait Anxiety Inventory (STAI, Spilberger, 1989) is a commonly used measure of trait and state anxiety. Form TX-2 is the most popular version which is also used in this research. It has 20 items for assessing trait anxiety. Trait anxiety items include: "I worry too much over something that really doesn't matter" and "I am content; I am a steady person." All 


\section{Epiphany: Journal of Transdisciplinary Studies}

items are rated on a 4-point scale (e.g., from "Almost Never" to "Almost Always"). Higher scores indicate greater anxiety. Considering our participants' background we used Turkish versions of both inventories, translated, adopted and already used in similar studies in Turkey. BDI has been adapted to Turkish language by Hisli (1989) and STAI has been adapted to Turkish language by Öner ve Le Comte (1983).

\section{Results}

Given our research aim, investigating depression and anxiety levels, central tendency measures, namely mean scores were, whose differences were further tested using t-test. Below are tables with of mean scores results and t-test results on depression level among both, experimental and control groups.

\begin{tabular}{|l|c|c|c|c|}
\hline \multicolumn{1}{|c|}{ Participants } & N & Mean & Std. & Std. Error \\
& Deviation & Mean \\
\hline $\begin{array}{l}\text { Depression total/ } \\
\text { Experimental group }\end{array}$ & 60 & 18,5000 & 7,31031 &, 94376 \\
\cline { 2 - 5 } $\begin{array}{l}\text { Depr total/ Control } \\
\text { group }\end{array}$ & 60 & 12,6667 & 5,74210 &, 74130 \\
\hline
\end{tabular}

Table 1. Depression level, mean scores for both groups.

Table one shows depression level mean scores and standard deviation of both, experimental and control group. Depression level mean scores of experimental group is 18.500 while the mean of control group is 12.667. 


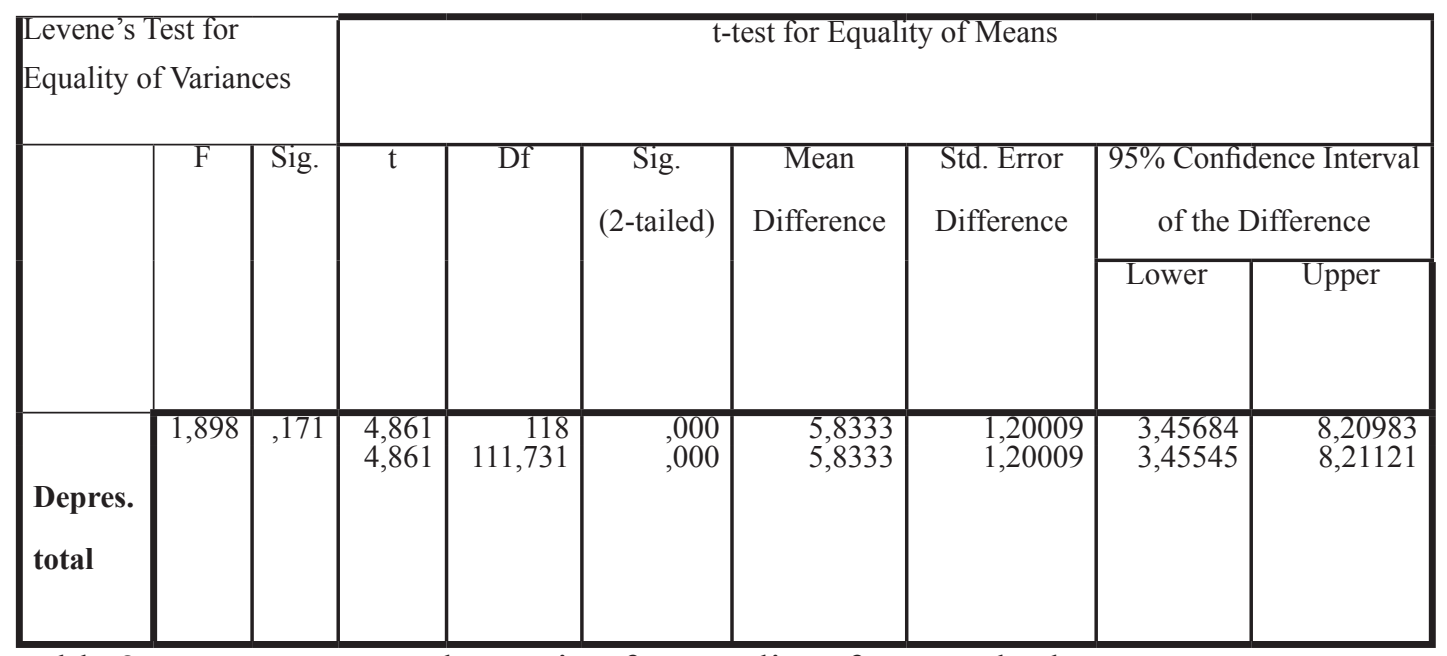

Table 2: T-test scores on depression for equality of means, both groups

Table two shows t-test results for depression for both control and experimental group. As we can see, sig.(2-tailed) the value is ,000 indicating statistically significant difference in depression scores between two groups. Anxiety levels were also measured and results are shown in the table below.

\begin{tabular}{|l|r|r|r|r|}
\hline \multicolumn{1}{|c|}{ Participants } & N & Mean & Std. Deviation & Std. Error Mean \\
\hline $\begin{array}{l}\text { Anxiety total/ } \\
\text { Experimental group }\end{array}$ & 60 & 40,7667 & 10,77091 & 1,39052 \\
\cline { 2 - 5 } & 60 & 32,4000 & 7,80309 & 1,00737 \\
$\begin{array}{l}\text { Anxiety total/Control } \\
\text { group }\end{array}$ & & & & \\
\hline
\end{tabular}

Table 3: Anxiety level, mean scores for both groups

This table shows mean scores and standard deviation for anxiety level of both experimental and control groups. As we can see, anxiety mean scores of the experimental group is 40, 7667 while mean scores results for control group is 32.4. Significance was further tested with $\mathrm{t}$-test and table 
below shows results.

\begin{tabular}{|c|c|c|c|c|c|c|c|c|c|}
\hline \multicolumn{3}{|c|}{$\begin{array}{c}\text { Levene's Test for } \\
\text { Equality of Variances }\end{array}$} & \multicolumn{7}{|c|}{ t-test for Equality of Means } \\
\hline & $\mathrm{F}$ & Sig. & $\bar{t}$ & Df & Sig. & $\begin{array}{c}\text { Mean } \\
\text { Difference }\end{array}$ & $\begin{array}{l}\text { Std. Error } \\
\text { Difference }\end{array}$ & $\begin{array}{r}95 \% \text { C } \\
\text { Interv } \\
\text { Diff }\end{array}$ & $\begin{array}{l}\text { nfidence } \\
1 \text { of the } \\
\text { rence }\end{array}$ \\
\hline & & & & & & & & Lower & Upper \\
\hline $\begin{array}{l}\text { Anxiety } \\
\text { total }\end{array}$ & 8,332 &, 005 & $\begin{array}{l}4,873 \\
4,873\end{array}$ & $\begin{array}{r}118 \\
107,556\end{array}$ & $\begin{array}{l}, 000 \\
, 000\end{array}$ & $\begin{array}{l}8,36667 \\
8,36667\end{array}$ & $\begin{array}{l}1,71707 \\
1,71707\end{array}$ & $\begin{array}{l}4,96639 \\
4,96297\end{array}$ & $\begin{array}{l}11,76694 \\
11,77036\end{array}$ \\
\hline
\end{tabular}

Table 4: T-test results for both groups

In the independent t-test testing, two unrelated groups on the same continuum were compared. As we can see, 005 which is equal to 005 which means that the variances are at the limit of homogeneity, but in the sig.(2-tailed) the value is, 000 , what indicates a statistically significant difference between two groups when anxiety levels were compared. 


\section{DISCUSSION}

The aim of this study was to investigate depression and anxiety levels among chronic kidney patients. We used quasi-experimental research design whereby, from a total of 120 participants, we had 60 chronic kidney patients in the experimental group and 60 from general (no kidney failure diagnosis) in the control group. To measure depression Beck Depression Inventory and The State-Trait Anxiety Inventory were used to measure depression and anxiety levels. Since our aim was to investigate depression and anxiety levels among people with chronic kidney disease and no chronic kidney disease, which were the only selection criteria and no additional demographic information was inquired from participants.

\section{Depression level in among chronic kidney patients and control group}

As hypothesized, we found higher depression levels in the experimental group, among chronic kidney patients when compared to control group. Results indicate depression mean scores of experimental group 18.5, and 12. 66 in control group. Results of t-test indicate $p=, 000$ which less than 0.05 indicating statistically significant difference in means results between the groups. We can here say that the average of the experimental group from BDI match the criteria of depression according to BDI scoring. Our results match similar previous research and studies which also showed higher depression rates among CKD.

Chronic illnesses are difficult to cope with. From the beginning to the end, 
chronic diseases indicate many challenges and problems for a patient with chronic illness diagnosis. Life quality of people with chronic kidney failure is negatively affected due to serious physical changes, losing strength, fear of death, fear of losing a job. CKD patients are mostly treated with hemodialysis, scheduled by the hemodialysis services and as expected, their lives are shaped by the disease, its treatment, and outcome. Several similar studies are in line with this study. For example, Chang et al., (2013) conducted a study with $270 \mathrm{CKD}$ patients and found 61 individuals met the criteria for depression based on the Taiwanese Depression Questionnaire, which translates to a crude prevalence of $22.6 \%$. Also, Stasiak et al., (2014) conducted a study Brasil 128 CKD patients and also found 22.6\% of hemodialysis patients suffering from depression.

Boing et al., (2012) conducted a study on 1720 chronic kidney disease patients and found $16.2 \%$ prevalence of depression of among women, older individuals, widowed or divorced, and poor ones, and even after adjustment for confounders, the prevalence of depression was 1.44 times higher among those reporting one chronic disease and 2.25 times higher among those reporting two or more diseases when compared to those with no diseases. Thus, chronic disease(s) are factors in depression alongside socio-economic factors, family factors, income and age that possibly contribute to the development of depression.

Egede (2007) conducted a study in the United States, comparing one-year prevalence of depression in 10,500 patients who have chronic diseases, matching them with a healthy control group and results point that patients 
were three times more likely to be depressed. Depression rate was two times more present among patients with hypertension, diabetes, coronary artery disease, and heart failure while the rate is three times higher among end-stage renal disease, chronic obstructive pulmonary disease and cerebrovascular disease patients (Egede, 2007). Studies also indicate more depression among children suffering from chronic kidney disease. For example, Kogon et al., (2013) conducted a cross-sectional on 44 patients aged 9-18 years with chronic kidney disease and found $30 \%$ overall prevalence of depression, indicating that depression is a common issue even for children with chronic kidney disease. Based on the study, we might say that not only adults but also children might face depression due to chronic kidney disease and its outcomes.

A possible explanation of high prevalence of depression among chronic kidney disease patients lies in the fact that kidney disease is very challenging disease requiring serious, ongoing and demanding treatment techniques which might be factors contributing to patients depression level. Chronic kidney disease is most commonly efficiently treated with kidney transplantation however, studies state depression might continue even after the transplantation, as demonstrated by Müller and his colleague (2015) study. Similarly, Corruble et al., (2010) conducted a study with 390 chronic kidney disease patients from waiting-list for kidney transplantation whose depression levels were measured in three periods of time; when they are added to the list, 12 months later, 24 months later and 3 months after transplantation, and found that depressive symptoms progressively 
increased before transplantation and showed a marked decrease after transplantation.

Given the chronic nature of illness itself, necessary and requiring treatment procedures, patients with chronic kidney disease must face serious life changes and constraints. Although the best treatment for chronic kidney failure is kidney transplantation the number of transplants is low and many patients end up on waiting-list, patients sometimes wait for years to be transplanted. This kidney transplant waiting process poses serious mental health threats appearing in a form of anxiety, negative thinking, pessimism, hopelessness, which could be serving as roots for depression development. Thus, it is no surprise that depression is not only common but most common mental health condition among chronic kidney disease patients. Besides, patients' individual and social /professional life is negatively affected by the disease itself and the schedule for a dialysis process. The average schedule of a patient is 3 days per week and spending 4 hours in hospitals or dialysis services per each day, what negatively interferes with patients daily functioning, preventing patient to have full social and occupational activities. At the same time, being at the hospital and hospital environment itself might influence patients thinking, reminding them of their illness and inability to have a normal fulfilling life and even the fear for their future if they do not receive treatment. This might be also the reason that patients lose their hope and become hopeless, factors underling depression.

At the same time, chronic kidney disease patients lose strength and face having serious physical changes and constrain in their bodies. Patient's 
inability to do the things he/she used to do before the illnesses might instill negative thinking about themselves and their capabilities or even the fear of losing more strength, making them vulnerable and necessitating help from others, making them dependent. Being dependent on others, after someone was able to function independently, is a significant factor which might negatively contribute the state of mind (especially man). Independence and physical strength is especially important to men since most cultures and traditions expect a man to take care of others rather than to be taken care of. Besides depression, facing chronic illness diagnosis leads to anxiety because diagnosis indicates a new phase of life with a serious, chronic condition and disease, which is restraining in nature and with troubled and uncertain future. Inability to picture the future and have many questions about the disease is natural but might be anxiety provoking. Uncertainty and anxiety might be factors which might turn into depression after a while. However, it should also be noted that there are other factors which contribute to depression development which we did not include as variables in our study, factors such as, presence of other chronic or non chronic illnesses, gender, marital status, socio-economic status and income, family relationships etc, which could also have played a role in depression level among our participants

\section{Anxiety levels among chronic kidney patients and the control group}

As hypothesized, chronic kidney patients scored higher on anxiety in comparison to the general population, control group. Anxiety levels mean 
scores for the experimental group is 40.76 and mean scores of 32.30 in the control group. T-test results indicate $p=, 000$ which less than 0.05 , indicating the statistically significant difference between experimental and control group. Thus, the second hypothesis is also accepted showing higher anxiety levels among chronic kidney patients when compared to control group.

Ottaviani et al., (2016) conducted asimilar study with 100 chronic kidney disease patients in Sao Paulo, Brazil, finding 33.0\% of chronic renal patients diagnosed with anxiety. Theofilou (2011), conducted similar study 144 patients and found women presented significantly higher scores than men in trait anxiety measured by STAI II.

Müller and colleagues (2015) concluded anxiety to be surprisingly constant after and before the transplantation. Corruble et al., (2010) measured anxiety levels in three periods of time, when they are added to the list, 12 months later, 24 months later and 3 months after transplantation on 390 chronic kidney disease patients from waiting-list for kidney transplantation and found that anxiety symptoms progressively increased before transplantation and showed a marked decrease after transplantation.

In addition, Lee (2013) has conducted a study with 208 pre-dialysis chronic kidney patients and found $27.6 \%$ anxiety prevalence among these patients. Cukor and colleagues (2008) with their study show $45.7 \%$ of chronic kidney disease patients have met the criteria for anxiety disorder, with specific phobias of $26.6 \%$ as most prevalent one followed by $21 \%$ of panic disorder. Besides, chronic kidney disease interferes with other bodily functions. 
For example, Turkish Kidney Foundation (2012) indicate sexual dysfunction among chronic kidney disease patients, what further creates marital problems, pointing to $70 \%$ of male patients having impotence issues and around $50 \%$ having marital problems. So, chronic kidney disease is also related to sexual problems marital problems, which additionally complicate already vulnerable physical and mental health of chronic kidney patients. Although we did not investigate these variables, it is possible that they could have influenced study results.

Hence, in line with previous studies, the prevalence of anxiety is quite high among chronic kidney disease patients. Facing chronic illness diagnosis requires different coping skills. Poor or lack of effective coping strategies and skills might be anxiety provoking. Adaption to this new stressful situation is hard, not only for the patient but also his/her family members as well. Disease outcomes like physical changes, itching, sleeping problems, and sexual problems cannot be controlled by the patients, which in turn might make patients anxious, lonely and hopeless. Feeling lonely and isolated pushes patients away from family members and friends, because patients might be feeling uncomfortable to talk about the illness and its outcomes in order to avoid worrying family members. Chronic illness diagnosis usually induces fear and anxiety due to the fear about the future, wondering what will happen and become of them. At the same time, some studies indicate about $57 \%$ of depression cases showed evidence of comorbid anxiety, while only $28 \%$ of those with clinically significant anxiety had concurrent depression. So, comorbidity of mental health disorders is common for 


\section{Epiphany: Journal of Transdisciplinary Studies}

patients with chronic disease (Braam et al., (2014).

Still, we ought to acknowledge the possibility of other factors contributing to anxiety development like genetics, gender, age, life quality, family and social support, which we did not include in our study, which might be having a role in our study results and should be included in the future study. Family support and lack of it plays a significant role in disease recovery and mental health problems prevention. Family members play a very important role and also should be included to help chronic kidney disease patients because the entire family is somehow influenced by the disease.

\section{Conclusion}

Depression and anxiety are the most common mental health disorders to be found among chronic kidney disease patients. Possible reasons for anxiety and depression development among chronic kidney disease patients lies partially in the disease itself, partially in treatment techniques commonly used to treat this condition and partially in disease's overall aftermath. Given the prevalence of depression and anxiety disorders among chronic kidney disease patients hospital services should offer psychological support and help to patients suffering from chronic kidney disease as well as their family members and some sort of holistic service. Besides diminishing and treating chronic illness and relieve negative outcomes of disease and its treatment, a holistic approach could be very useful in helping patients and family members cope on individual and group level. 


\section{References}

1. Almeida OP, Draper B, Pirkis J, Snowdon J, Lautenschlager NT, Byrne G, Sim M, Stocks N, Kerse N, Flicker L, Pfaff JJ (2012). Anxiety, depression, and comorbid anxiety and depression: risk factors and outcome over two years International Psychogeriatr. (10):pg.1622-32.

2. Çelik, H. C., \& Acar, T.(2007). Kronik Hemodiyaliz Hastalarında Depresyon ve Anksiyete Düzeylerinin Çeşitli Değişkenlere Göre Incelenmesi. Firat T1p Dergisi 2007;12(1): 23-27.pg.

3. Debjit Bhowmik K.P. Sampath Kumar, Shweta Srivastava, Shravan Paswan, Amit Sankar (2012). Dutta Depression -Symptoms, Causes, Medications and Therapies Coimbatore medical college, Coimbatore, Tamil Nadu, India Vol. 1 No. 3

4. Antonio Fernando Boing AF et al., (2012). Association between depression and chronic diseases: results from a population-based study. Revista de Saúde Pública Vol.46 No.4 doi: 10.1590/S003489102012005000044

5. Bossola M, Ciciarelli C, Stasio D, Conte GL, Vulpio C, Luciani G, Tazza L(2010). Correlates of symptoms of depression and anxiety in chronic hemodialysis patients. Journal Brasileiro de Nefrologia. vol.36 no.3, Pg.4.

6. Braam AW, Copeland JR, Delespaul PA, Beekman AT, Como A, Dewey M, Fichter M, Holwerda TJ, Lawlor BA, Lobo A, Magnússon H, Prince MJ, Reischies F, Wilson KC, Skoog I (2014). Depression, subthreshold depression and comorbid anxiety symptoms in older Europeans: results from the EURODEP concerted action. Journal of affective disorders..155:266-72. doi: 10.1016

7. Cates, M., Wells, B. G., \& Thatcher, G. W. (1996). Anxiety Disorders. In E. T.Herfindal and D. R. Gourley (Eds.). Textbook of Therapeutics: Drug and Disease Management (6th ed., pp. 10731093). Hagerstown, MD: Lippincott Williams and Wilkins.

8. Clark, L. A., \& Watson, D. (1991). Tripartite model of anxiety and depression: Psychometric evidence and taxonomic implications. Journal of Abnormal Psychology, 100, 316-336.

9. Chang CK HR, Broadbent M, Fernandes AC, Lee W, Hotopf M, Stewart R.(2010). All-cause mortality among people with serious mental illness (SMI), substance use disorders, and depressive 
disorders in southeast London: a cohort study. BioMedCentral Psychiatry. 10:77. doi:10.1186.

10. Corruble E, Durrbach A, Charpentier B, Lang P, Amidi S, Dezamis A, Barry C, Falissard B.(2010). Progressive increase of anxiety and depression in patients waiting for a kidney transplantation. Behavioralmedicine. 2010, Jan-Mar;36(1):32-6.Pg.abstract doi:10.1080.

11. Cukor, D., Coplan, J., Brown, C., Friedman, S., Newville, H., Safier, M., et al. (2008). Anxiety disorders in adults treated by hemodialysis: a single-center study. Clinical journal of the American Society of Nephrology. 2008 Nov; 3(6): 1752-1758. doi: 10.2215.

12. Cyranowski JM, Schott LL, Kravitz HM, Brown C, Thurston RC, Joffe H, Matthews KA, Bromberger (2012). JT Psychosocial features associated with lifetime comorbidity of major depression and anxiety disorders among a community sample of mid-life women: the SWAN mental health study. Depress Anxiety. 2012;29(12):1050. doi: $10.1002 /$ da.21990.

13. Wioletta Dziubek, Joanna Kowalska, Mariusz Kusztal, Łukasz Rogowski, Tomasz Gołębiowski, Małgorzata Nikifur, Joanna Szczepańska-Gieracha, Agnieszka Zembroń-Łacny, Marian Klinger, Marek Woźniewski(2015). The Level of Anxiety and Depression in Dialysis Patients Undertaking Regular Physical Exercise Training -a Preliminary Study Kidney Blood Press Res 41:86-98 DOI: $10.1159 / 000368548$

14. Dworkin S, von Korff M, LeResche L.(1990). Multiple pains, psychiatric and psychosocial disturbance: an epidemiologic association. Archives of general psychiatry. Retrieved from https:// www.ncbi.nlm.nih.gov/pubmed/2306165

15. Egede LE.(2007).Major depression in individuals with 1. chronic medical disorders: prevalence, correlates and association with health resource utilization, lost productivity and functional disability. General hospital psychiatry. Retrieved from; https://www.ncbi.nlm. nih.gov/pubmed/17888807

16. Eisenberg, D. M., Davis, R. B., Ettner, S. L., Appel, S., Wilkey, S., \& Van Rompay, M. (1998). Trends in alternative medicine use in the United States. The Journal of the American Medical Association, 280(18), 1569-1575.

17. Finkelstein,F.O., \& Finkelstein,S.H.(2016). Depression in chronic 
dialysis patients: Assessment and treatment. Vol:15 No:12.

18. Joseph Goldberg, MD on (2016). The detection and treatment of depression in the physically ill. World Psychiatry 2010 Feb; 9(1): $16-20$

19. Hedayati SS, Minhajuddin AT, Toto RD, Morris DW, Rush AJ.(2009). Prevalence of major depressive episode in CKD American journal of kidney diseases: the official journal of the National Kidney Foundation. (3): pg: 424-432. doi: 10. 1053/ j. ajkd. 2009. 03.017.

20. Kocabaşoğlu N, Doksat MK, Doğangün B.(2004). Anksiyete ve Depresyonun Çok Yönlü İlişkisi, Yeni Symposium. 42: 168-176.

21. Wayne J. Katon, (2011). Epidemiology and treatment of depression in patients with chronic medical illness, Dialogues in Clinical Neuroscience. 2011 Mar; Vol.13,No.1:

22. Amy J. Kogon, Ann Vander Soep, Noel S. Weiss, Jodi Smith, Joseph T. Flynn, Elizabeth McCauley (2013). Depression and its associated factors in pediatric chronic kidney disease, International Pediatric Nephrology, September; 28(9):Pg. 1855-1861. doi:10.1007/s00467013-2497-5.

23. Lee YJ1, Kim MS, Cho S, Kim SR.(2013). Association of depression and anxiety with reduced quality of life in patients with predialysis chronic kidney disease. International journal of clinical practice. 2013 Apr; 67(4):pg.363-368. doi: 10.1111/ijcp.12020.

24. Lysaght MJ (2002). Maintenance dialysis population dynamics: current trends and long-term implications. Journal of the American Society of Nephrology 13:pg37-40.

25. Müller HH, Englbrecht M, Wiesener MS, Titze S, Heller K, Groemer TW, et al. (2015).Depression, Anxiety, Resilience and Coping Pre and Post Kidney Transplantation - Initial Findings from the Psychiatric Impairments in Kidney Transplantation., doi:10.1371/ journal.pone.0140706

26. Nesrin Hisli (1989). Beck depresyon envanterinin üniversite öğrencileri için geçerliliği.Bilkent Üniversitesi Psikolojik Danışmanlık ve Rehverlik Araştırma Merkezi. 7(10) pg:3-13.

27. Ana Carolina Ottaviani, Loren Carolina Betoni, Sofia Cristina Iost Pavarini Karina Gramani Say, Marisa Silvana Zazzetta, Fabiana de Souza Orlandi,(2016). Association Between Anxiety and Depression and Quality of Life of Chronic Renal Patients on Hemodialysis, 
25(3):e00650015

28. Prince M, Patel V, Saxena S et al.(2007). No health without mental health. Retrieved from; https://www.ncbi.nlm.nih.gov/ pubmed/17804063

29. Public Health Institution of Turkey. (2014). Prevention and Control Programme for Kidney Diseases Prevention and Control Programme of Turkey - Course of Action.

30. Funda Sar1, Fettah Fevzi Ersoy (2016). Drug Use in Chronic Kidney Disease.Turkish Nephrology, Dialysis and Transplantation Journal. Pg.1-10 doi: 10.5262/tndt.2016.01.

31. De Sousa (2008). Psychiatric issues in renal failure and dialysis. Indian Journal of Nephrology.18 (2): Pg.47-50. doi: 10.4103/09714065.42337

32. The Ministry of Health of Turkey, september, 2014. Rapor Bülteni Say1:1 Retrieved from; http://www.tkhk.gov.tr/ Dosyalar/61a60d6e4a9b41a6bc2a84935d7b24b2.pdf

33. Turkish Kidney Foundation (2012).Retrieved from;https:// www. tbv.com.tr

34. Paraskevi Theofilou (2011). Depression and Anxiety in Patients with Chronic Renal Failure: The Effect of Sociodemographic Characteristics International Journal of Nephrology Volume 2011, doi: $10.4061 / 2011 / 514070$.

35. Beck AT, Steer RA, Garbin MG. Psychometric properties of the Beck Depression Inventory: twenty-five years of evaluation. Clin Psychol Rev 1988;8:77-100

36. Spielberger, C. D. (1989). State-Trait Anxiety Inventory: Bibliography (2nd ed.). Palo Alto, CA: Consulting Psychologists Press. 